\title{
Plaque-size Mutants of the Cellular Slime Mould Dictyostelium discoideum
}

\author{
By W. F. LOOMIS JuN. \\ Department of Biology, University of California, La Jolla, \\ California 92037, U.S.A. \\ AND J. M. ASHWORTH \\ Department of Biochemistry, University of Leicester, \\ Leicester, England
}

(Accepted for publication 29 March 1968)

\begin{abstract}
SUMMARY
Strains of Dictyostelium discoideum with stable hereditable alterations in growth rate have been isolated on the basis of plaque size following treatment of the myxamoebae with nitrosoguanidine. Myxamoebae of five independently isolated strains which form small plaques were mixed in all possible pairs and allowed to develop. Eight of the ten pairs gave strains with the ability to form large plaques. Several large-plaque strains isolated from such mixtures were found to segregate small-plaque strains during vegetative growth. The results are consistent with the hypothesis that these large-plaque strains result from recombination or complementation in a genome derived at least partially from two parental strains.
\end{abstract}

\section{INTRODUCTION}

The solitary vegetative myxamoebae of the cellular slime mould Dictyostelium discoideum aggregate forming assemblies of about $5 \times 10^{5}$ myxamoebae when their bacterial food supply is exhausted. These aggregated myxamoebae then proceed through a complex series of morphological steps and eventually differentiate into either the stalk or the spore cells of the sorus (fruiting body). In a suitable environment the spores germinate to form the vegetative myxamoebae. Treatment of the myxamoebae with a mutagen has led to the isolation of strains with stable hereditable aberrations in the developmental sequence and indicated that many events in this sequence are genetically controlled (Sussman \& Sussman, 1953; Sussman, 1955; Yanagisawa, Loomis \& Sussman, 1967). Further genetic analysis of this system has been hampered by the lack of a mating system and the inability to select for recombinant strains.

Both haploid and diploid strains have been described (Wilson \& Ross, 1957; Sussman \& Sussman, 1962). Sussman \& Sussman (1963) have reported the isolation of a diploid strain, H-I, from a mixed culture of two strains, one of which forms a white, the other a brown sorus. This diploid strain forms sori with the wild type pigmentation (yellow). Strain H-I was found to give rise at a low frequency to haploid progeny, most of which display one of the parental pigmentations, but a few of which have the pigmentation of an apparent recombinant. The rarity of formation of stable diploid strains, the low frequency of segregation of haploid strains from diploids and the inability to select or enrich for pigment markers has precluded further investigation of this system 
We report the isolation of a novel class of mutants of Dictyostelium discoideum in which the growth rate is markedly decreased, giving rise to a characteristically small plaque-size. Under standard conditions, one wild-type cell in a population of $10^{5}$ mutant cells can be readily detected and its progeny isolated, thus permitting selection procedures to be devised for recombinational events. We present evidence which suggests that genetic recombination and/or complementation can occur with a low frequency in $D$. discoideum.

\section{METHODS}

Chemicals. $N$-Methyl- $N^{1}$-nitro $N^{1}$-nitrosoguanidine (NTG) was obtained from the Aldrich Chemical Co. (Milwaukee, Wisconsin, U.S.A.). Actidione (cycloheximide) was the gift of the Upjohn Co. (Kalamazoo, Michigan, U.S.A.).

Organisms. Strain NC-4 is a haploid strain of Dictyostelium discoideum isolated by Raper (1935). An actidione-resistant strain which forms brown sori was isolated from NC-4 following treatment with NTG by Drs K. Yanagisawa \& M. Sussman (personal communication); both strains were kindly given us by Dr M. Sussman.

Myxamoebae were grown on agar plates with Aerobacter aerogenes and allowed to develop at $22^{\circ}$ on Millipore filter supports (AABPO 47) as described by Sussman (1966), with the modification that the filters were washed in boiling water for $15 \mathrm{~min}$. and then stored in cold distilled water before use.

Genetic notation. No standard system of notation appears to exist for the various mutants of cellular slime moulds. In this paper we use the following symbols:

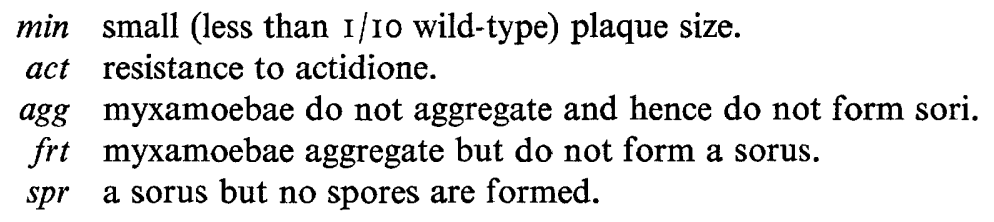

It is not known whether the various morphology markers are allelic. The probability is that they are not.

Clonal analysis. When less than $10^{4}$ wild-type myxamoebae or spores (or less than $10^{5} \mathrm{~min}$ cells) are spread on medium in a $9 \mathrm{~cm}$. diameter Petri dish the cells give definite plaques in the bacterial lawn (Sussman, 195I). To clone the myxamoebae a flamed platinum wire was touched to a plaque and then streaked on a growth plate previously spread with a heavy inoculum of Aerobacter aerogenes. After incubation for 2 days at $22^{\circ}$ confluent clearing of the bacterial lawn occurred at the start of the streak and isolated plaques arose further along the streak.

Mutagenesis. Vegetative myxamoebae were treated with NTG and then plated immediately as described by Yanagisawa et al. (1967).

Sensitivity to actidione. To distinguish between wild-type and act phenotypes, cells were either streaked or spread on a growth plate containing $500 \mu \mathrm{g}$. actidione $/ \mathrm{ml}$. and which had been previously innoculated with about $10^{8}$ Aerobacter aerogenes; act plaques were distinguishable after incubation for 3 days at $22^{\circ}$. 


\section{RESULTS}

\section{Isolation and characterization of min strains}

Myxamoebae of the brown actidione-resistant haploid strain derived from NC-4 were treated with nitroguanidine and spread at a density of $10^{3}$ myxamoeba per $9 \mathrm{~cm}$. diameter plate (Yanagisawa et al. 1967 ). After incubation for 3 days at $22^{\circ}$ there was a gradation in plaque size among the survivors. In a typical experiment with $91 \%$ killing, among 600 plaques measured, 30 had a diameter less than one-tenth that of an average wild-type plaque. Of these 30 , I5 stably inherited the small plaque size character $(\mathrm{min})$.

\begin{tabular}{|c|c|c|c|c|c|c|}
\hline \multirow[b]{2}{*}{ Strain } & \multirow{2}{*}{$\begin{array}{c}\text { Relative } \\
\text { size of } \\
\text { plaque } \\
\text { ( arbitrary } \\
\text { units) }\end{array}$} & \multirow[b]{2}{*}{ Morphology } & \multirow{2}{*}{$\begin{array}{c}\text { Drug } \\
\text { resistance }\end{array}$} & \multicolumn{3}{|c|}{ Reversion rates to } \\
\hline & & & & $\min ^{+}$ & $a c t$ & $\mathrm{frt}^{+}$ \\
\hline $\min ^{+}$stock & 100 & Wild type $\left(f r t^{+}\right)$ & act & - & -- & - \\
\hline $\min \mathrm{I}$ & 4 & Wild type $\left(f r t^{+}\right)$ & $a c t^{+}$ & $<5 \times 10^{-6}$ & $\mathrm{I} \cdot 4 \times 10^{-5}$ & - \\
\hline $\min 2$ & 4 & $\begin{array}{l}\text { No spores } \\
\text { formed }(s p r)\end{array}$ & act & $5 \times 10^{-6}$ & - & $5 \times 10^{-6}$ \\
\hline $\min 3$ & IO & Wild type $\left(f r t^{+}\right)$ & act & $5 \times 10^{-6}$ & - & - \\
\hline $\min 4$ & IO & $\begin{array}{l}\text { Aggregateless } \\
\text { (agg) }\end{array}$ & act & $5 \times 10^{-6}$ & - & $2 \times 10^{-2}$ \\
\hline $\min 5$ & IO & $\begin{array}{l}\text { Aggregateless } \\
\text { (agg) }\end{array}$ & act & $5 \times 10^{-6}$ & - & $<10^{-6}$ \\
\hline
\end{tabular}

When these 15 mutant strains were allowed to develop, it was noted that eight formed aberrant fruiting bodies. Reversion studies on five of these strains (Table $\mathrm{r}$ ) showed that the min mutant phenotypes reverted independently of, and with a frequency different from, the reversion frequencies of the other mutant phenotypes. It is possible that a second site mutation in the revertants resulted in alteration of only one expression of a pleiotrophic mutation. However, it is more probable that our conditions of mutagenesis often produced multiple mutational events in the same genome.

The genetic characteristics of the $5 \mathrm{~min}$ strains selected for further study are listed in Table I. The yellow colour of the wild-type strain NC-4 resides, almost exclusively, in the spore mass of the sori and is probably due to a carotenoid derivative (Staples \& Gregg, 1967). The vegetative myxamoebae never produced pigment and neither did the myxamoebae of any known agg derivatives of a yellow-pigmented strain, even when incubated in the absence of bacteria. The brown pigmented produced by our strain is of unknown chemical structure; it was produced by both agg and $\mathrm{rrt}^{+}$strains when incubated more than $24 \mathrm{hr}$ in the absence of bacteria. The pigment was excreted in large amounts and stained the agar a deep brown as well as causing the sori (when produced) to have a deep brown colour.

The reversion rates (Table I) were determined by plating myxamoebae on 20 growth plates at $5 \times 10^{4}$ viable myxamoebae/plate and scoring plaque size after incubation for 2 days at $22^{\circ}$. Plaques were scored $\mathrm{min}^{+}$when, on subculturing, they gave rise to plaques which were more than twice the size of those of the parental strain. Frequently $\mathrm{min}^{+}$revertants were isolated which produced plaques of a size intermediate between the original $\min$ strain and the wild type. These partial revertants of the min characteristic may have resulted from second site mutational events or complete reversion of 
one of several lesions which have a cumulative effect on the growth rate of the $\min$ strains. The reversion rates of the various markers were quite different and independent. No $\mathrm{agg}^{+}$revertants of $\min 5$ were observed.

\section{Isolation and characterization of $\mathrm{min}^{+}$progeny from min strains}

The five $\min$ strains described in Table I were grown separately, washed free of bacteria, mixed in equal proportions in all possible pairs and allowed to develop on Millipore filter supports at $22^{\circ}$. Sori were formed in all cases after $22 \mathrm{hr}$ with the exception of the pair $\min 4+\min 5$. Cells were washed off the Millipore supports at the time of deposition and after incubation for more than $22 \mathrm{hr}$ were plated on at least three plates at $10^{3}$ cells/plate. Viability was greater than $80 \%$ initially but decreased to about $50 \%$ after $22 \mathrm{hr}$.

Table 2. Dictyostelium discoideum: the isolation of $\mathrm{min}^{+}$strains from mixtures of min mutants

$\begin{array}{lccc}\text { Parental strains } & \begin{array}{c}\text { No. of } \\ \text { experiments }\end{array} & \begin{array}{c}\text { No. of } \min ^{+} \\ \text {isolates }\end{array} & \begin{array}{c}\text { Frequency of } \\ \min ^{+} \text {isolates }\end{array} \\ \min 1+\min 2 & 3 & 5 & 6 \cdot 2 \times 10^{-4} \\ \min 1+\min 3 & 3 & 60 & \mathrm{I} \cdot 1 \times 10^{-2} \\ \min 1+\min 4 & 2 & 2 & 3.8 \times 10^{-4} \\ \min 1+\min 5 & 7 & 65 & 3 \cdot 2 \times 10^{-3} \\ \min 2+\min 3 & \mathrm{I} & 2 & 6 \cdot 7 \times 10^{-4} \\ \min 2+\min 4 & \mathrm{I} & 8 & 3.2 \times 10^{-3} \\ \min 3+\min 4 & 2 & 0 & <2 \times 10^{-4} \\ \min 5+\min 2 & 2 & 4 & 7 \cdot 3 \times 10^{-4} \\ \min 5+\min 3 & \mathrm{I} & 2 & \mathrm{I} \cdot 3 \times 10^{-2} \\ \min 5+\min 4 & 2 & 0 & <4 \times 10^{-4}\end{array}$

Table 3. Dictyostelium discoideum: phenotypes of $\min ^{+}$progeny

\begin{tabular}{|c|c|c|c|c|c|}
\hline Parental strains & $\begin{array}{c}\text { Experi- } \\
\text { ment } \\
\text { no. }\end{array}$ & $\begin{array}{c}\text { Total } \\
\text { no. of } \\
\text { plaques }\end{array}$ & $\begin{array}{l}\text { Frequency of } \\
m^{+} \text {plaques }\end{array}$ & $\begin{array}{l}\text { Phenotypes of } \\
\text { min }^{+} \text {plaques }\end{array}$ & $\begin{array}{c}\text { No. } \\
\text { observed }\end{array}$ \\
\hline $\begin{array}{l}\min \text { I } \text { act }^{+} \mathrm{frt}^{+}+ \\
\min 5 \text { act agg }\end{array}$ & $\begin{array}{l}\text { I } \\
2 \\
3\end{array}$ & $\begin{array}{r}5000 \\
6000 \\
800\end{array}$ & $\begin{array}{l}6 \times 10^{-4} \\
7 \times 10^{-4} \\
5 \times 10^{-3}\end{array}$ & $\begin{array}{l}\mathrm{frt}^{+} \text {act } \\
\text { agg act } \\
\text { agg act } \\
\text { frt }^{+} \text {act } \\
\text { a }^{+}\end{array}$ & $\begin{array}{l}3 \\
4 \\
3 \\
\text { I }\end{array}$ \\
\hline $\min$ I act $^{+} \mathrm{frt}^{+}+$ & I & 5000 & $4 \times 10^{-4}$ & $\mathrm{frt}^{+}$act & 2 \\
\hline $\min 2$ act spr & 2 & 2000 & $1.5 \times 10^{-3}$ & spr act & 3 \\
\hline $\min _{a c t} a^{2 c t^{+}+} \min 3$ & I & 2500 & $2 \times 10^{-2}$ & act & 5 \\
\hline
\end{tabular}

No large plaques were observed from cells of any of the pairs when plated out shortly after deposition on the Millipore supports, nor from any of the min strains allowed to develop separately; but cells from all pairs, except for two ( $\min 4+\min 5$ and $\min 3+\min 4$ ), gave a few large plaques when plated after $22 \mathrm{hr}$ of development. The frequency with which large plaques occurred varied from experiment to experiment (Table 3) and varied even more widely according to the pair under study (Table 2).

The apparent $\mathrm{min}^{+}$progeny from each pair were picked and streaked on fresh plates alongside both parental and wild-type strains. After incubation for 3 days, plaque size was measured and only those isolates which formed plaques at least twice the 
size of the largest parental strain were scored as $\mathrm{min}^{+}$. All $\mathrm{min}^{+}$isolated formed the dark-brown pigment. It was noticed that the majority of the original isolates gave many $\mathrm{min}^{+}$plaques when streaked, but also gave plaques the same size of the parental strain. These small plaques were unlikely to have arisen by contamination of the original isolate by parental cells and it seems likely that many $\mathrm{min}^{+}$progeny are unstable and segregate the parental $\mathrm{min}$ character (see below).

Where appropriate the $\mathrm{min}^{+}$progeny were also analysed for the unselected markers $a c t^{+}, a g g$ and $\mathrm{spr}^{+}$; the results of these experiments are summarized in Table 3. The $\min ^{+}$progeny from mixtures of $\min \mathrm{I}$ and either $\min 5$ or $\min 2$ were of both parental phenotypes as regards drug resistance and morphological development. It can also be seen that the act and various morphological markers were not randomly distributed among the $\mathrm{min}^{+}$progeny, at least in the small number of isolates examined.

\section{Table 4. Dictyostelium discoideum: segregation of $\mathrm{min}^{+}$strains}

\begin{tabular}{|c|c|c|}
\hline Parental strains & $\begin{array}{l}\text { Phenotype of } \\
\mathrm{min}^{+} \text {isolate }\end{array}$ & $\begin{array}{l}\text { Phenotype of } \\
\text { segregants observed }\end{array}$ \\
\hline $\begin{array}{l}\min 1+\min 3 \\
\min 1+\min 5\end{array}$ & $\begin{array}{l}\mathrm{frt}^{+} \mathrm{act}^{+} \\
\mathrm{frt}^{+} \mathrm{act}+\end{array}$ & $\begin{array}{l}\min \mathrm{frt}^{+} a c t^{+} \\
\text {min }_{\text {frt }}^{+} a c t^{+} \\
\text {min }^{+} \text {frt act }\end{array}$ \\
\hline $\min 1+\min 3$ & $\mathrm{frt}^{+} \mathrm{act}$ & $\min$ frt $^{+}$act \\
\hline
\end{tabular}

\section{Segregation from $\mathrm{min}^{+}$strains}

As mentioned previously, the first streak of many of the $\mathrm{min}^{+}$isolates gave both large and small plaques. When these plaques were in turn plated out, all the smallplaque isolates bred true as did some of the large-plaque isolates. However, many of the subcloned $\mathrm{min}^{+}$isolates continued, on further clonal analysis, to give both large-plaque and small-plaque strains. Several of these unstable $\mathrm{min}^{+}$isolates were analysed for segregation of the $\mathrm{min}$ character and, where appropriate, for the unselected characters. The results of these experiments are summarized in Table 4 ; min segregants were observed to occur at frequencies from 30 to $70 \%$ from different $\mathrm{min}^{+}$isolates. It is clear that many of the $\mathrm{min}^{+}$isolates segregated $\min$ progeny and the plaque-size phenotype segregated independently of drug resistance or morphological phenotype.

\section{DISCUSSION}

The biochemical mechanism(s) causing the slow growth rate and consequent $\mathrm{min}$ phenotype in Dictyostelium discoideum are unknown and likely to be complex. The myxamoebae are grown in a very rich medium containing bacteria as well as a high concentration of peptone and yeast extract. Thus, the growth rate is probably not restricted by limited availability of biosynthetic intermediates. The frequent occurrence of the min phenotype among mutagen-treated myxamoebae and the gradation of plaque sizes among separate $\min$ isolates suggest that any one of a number of mutations may cause the min character.

All the min strains described here are derivatives of the same strain. Since most of them will give $\mathrm{min}^{+}$descendants when allowed to develop in association, it is clear that recombinant progeny can arise in the absence of a clearly defined stable mating system. However, the frequency with which such $\mathrm{min}^{+}$isolates were produced varied 
widely from experiment to experiment with the same pair and varied even more widely between different pairs, suggesting that some physiological state of competence or compatibility is involved.

One of the pairs which failed to give rise to observable $\min ^{+}$isolates $(\min 3+\min 4)$ formed sori,but the ratio of parental phenotypes among spores of this pair was found to differ greatly from the ratio in which the myxamoebae were mixed. It appears that the association of cells of this pair is not an efficient or equal one. The other pair which failed to give rise to observable $\min ^{+}$isolates ( $\min 4+\min 5$ ) did not form sori. It is possible that the varying frequencies reported in Table 3 reflect the efficiency with which the various strains form mixed sori.

Since random assortment of unselected characters was not observed among various $\mathrm{min}^{+}$isolates (Table 3 ), reciprocal recombination appears unlikely in the formation of $\mathrm{min}^{+}$progeny. Complementation of two complete genomes from min parental strains cannot account for the $\mathrm{min}^{+}$progeny since both $\mathrm{min}^{+}$act and $\mathrm{min}^{+}$act ${ }^{+}$strains may be obtained from the same pair of min parents (Table 3). However, recombination or complementation of partial genomes can account for our results. It is interesting that several of our $\mathrm{min}^{+}$isolates were found to form spores whose size distribution was closer to that reported by Sussman \& Sussman (1962) for diploid spores than for haploid spores (W. F. Loomis, unpublished). The majority of the $\mathrm{min}^{+}$isolates, however, form spores with a haploid size distribution and these may be the result of recombinational events and haploidization.

We thank Dr M. Sussman for introducing us to the study of this organism. The expert technical assistance of Miss Karen Howard is gratefully acknowledged. One of us (J. M. A.) was a Harkness Fellow of the Commonwealth Fund during part of the work reported here. This study was supported by Grant GB-5830 from the National Science Foundation, U.S.A., to W.F.L. and by Grant B/SR/4260 from the Science Research Council, Great Britain to J.M.A.

\section{REFERENCES}

RAPER, K. (1935). Dictyostelium discoideum, a new species of slime mold from decaying forest leaves. J. agric. Res. 50, 135.

Staples, S. \& GregG, J. (1967). Carotenoid pigments in the cellular slime mold Dictyostelium discoideum. Biol. Bull. mar. biol. Lab., Woods Hole 132, $4 \mathbf{1} 3$.

Sussman, M. (195I). The origin of cellular heterogeneity in the slime mold, Dictyosteliaceae. J. exp. Zool. $\mathbf{1 8}$, 407.

Sussman, M. (I955). 'Fruity' and other mutants of the cellular slime mold, Dictyostelium discoideum: a study of developmental aberrations. J. gen. Microbiol. 13, 295.

Sussman, M. (1966). Methods in Cell Physiology, chap. 14. New York: Academic Press.

Sussman. M. \& Sussman, R. (1953). Cellular differentiation in Dictyosteliaceae: heritable modification of the developmental pattern. Ann. N.Y. Acad. Sci. 56, 949.

Sussman, M. \& Sussman, R. (1962). Ploidal inheritance in Dictyostelium discoideum: stable haploid, stable diploid and metastable strains. J. gen. Microbiol. 28, 417.

Sussman, R. \& Sussman, M. (1963). Ploidal inheritance in the slime mold Dictyostelium discoideum: haploidization and genetic segregation of diploid strains. J. gen. Microbiol. $3^{0}, 349$.

Wilson, C. \& Ross, I. (1957). Further cytological studies in the Acrasiales. Am. J. Bot. 44, 345 .

Yanagisasa, K., LoOmis, W. F. Jun. \& Sussman, M. (1967). Developmental regulation of the enzyme UDP-galactose polysaccharide transferase. Expl cell Res. 46, 329. 